\title{
Proyectos para la formación docente: recorridos y desafíos
}

Victoria Baraldi ${ }^{(1)}$

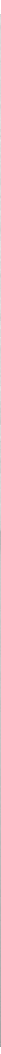


La celebración de "Ios 20" invita a una mirada reflexiva sobre nuestra institución. Para ello, es propicio recordar que estas dos décadas de funcionamiento como Facultad, se asientan sobre una vasta trayectoria institucional abocada a la formación de docentes. Lo que hoy denominamos Facultad de Humanidades y Ciencias, tiene como antecedente inmediato a la Facultad de Formación Docente en Ciencias, y ésta a la Escuela Universitaria del Profesorado que a su vez se constituye sobre la base del Instituto del Profesorado Básico, nacido sobre el inicial Instituto del Profesorado allá por el año $1953^{(2)}$.

Quienes fueron protagonistas de los trayectos precedentes y quienes los conocimos a través de los relatos y de la investigación, sabemos no sólo de las múltiples denominaciones de esta institución y de sus cambiantes dependencias, sino, y por sobre todo, de los diversos proyectos educativos plasmados en sintonía con los momentos sociales y políticos por los que atravesaba el país y al calor de las luchas y debates internos.

No es el momento aquí de analizar cada uno de los proyectos curriculares que se implementaron, algo de eso se hizo en otra oportunidad, pero sí advertir que así como algunos de ellos se sostuvieron para reproducir un orden social vigente, otros bregaron por hacer de este espacio de educación superior, un lugar de transformación educativa. Sus luchas y aspiraciones, aunque interrumpidas, dejaron sus ecos hasta hoy.
(1) Docente integrante del INDI - FHUC - UNL (2) Un detalle de sus transformaciones y proyectos educativos puede consultarse en: Baraldi, Victoria (1996) El lugar de la didáctica en la formación docente. Historia de una problemática compleja. Santa Fe, Universidad Nacional del Litoral. 
En estos días celebramos la consolidación de 20 años de Facultad, pero por sobre todo, celebramos el conjunto de procesos y de logros que esto significó para la vida académica. Aun cuando la lista sea extensa, y se corra el riesgo de ser incompleta, no podemos dejar de mencionar la importancia del cogobierno, el acceso a las cátedras por concursos, el fortalecimiento de los proyectos de investigación y de extensión, la apertura de nuevas carreras y cursos de perfeccionamiento, la apertura de maestrías y especializaciones, la incorporación de carreras y cursos con modalidad a distancia, la realización de convenios con otras instituciones y servicios a terceros, la realización de encuentros, jornadas y congresos nacionales e internacionales, no sólo los referidos a la formación docente, sino también aquellos vinculados al conjunto de las licenciaturas que se han implementado. Es ineludible mencionar, casi como evidencia de este crecimiento, el confortable y moderno edificio que alberga no sólo a docentes, no docentes y estudiantes sino a todos aquellos que son convocados a participar de la vida académica de la facultad.

El mirar hacia atrás promueve un doble movimiento. Por un lado, permite visualizar el fortalecimiento institucional y la consolidación de viejas aspiraciones que han sido logradas, pero también admite apuntar aquellas cuestiones no resueltas, muchas de las cuales no son exclusivas de esta institución, sino que pesan sobre el conjunto de las universidades públicas argentinas. En esta otra lista, podemos mencionar, sin rigor de exhaustividad: la dificultad en el acceso real al derecho de la educación superior de las mayorías; las condiciones de trabajo docente; ciertas representaciones sociales que algunos sectores tienen acerca de la universidad; el sesgo profesionista de las carreras; la fragmentación de los tiempos y espacios individuales que dificultan la consolidación de proyectos colectivos. "Males de época", problemas de la educación superior históricamente no resueltos y nuestra propia idiosincrasia tejen esta vida cotidiana que a veces por urgente y exigente nos exime del pensar.

Nos preguntamos entonces, si esta detención en el tiempo, este mirar hacia atrás y hacia adelante, no sería propicio para compartir inquietudes y preguntas. En fin, seguir debatiendo acerca del sentido y el tipo la formación 
que estamos propiciando en nuestros estudiantes universitarios. Ante una realidad tan compleja y desafiante es necesario que nos cuestionemos si estamos dotando a nuestros alumnos de herramientas teóricas y metodológicas que les permita analizar los problemas estructurales de nuestra historia social y educativa, no sólo de comprender el presente, sino involucrarse en proyectos colectivos. Hemos de promover que, al mismo tiempo que se apropian de nuevos lenguajes puedan analizar críticamente el conjunto de "verdades" que promueven los medios de comunicación. Además continuar generando los espacios para que se interroguen acerca del sentido social de su futura práctica laboral como otras de las tareas ineludibles. El título de un libro: Para enseñar no basta con saber la asignatura, hoy sigue teniendo vigencia. Podríamos parafrasearlo y decir, para ser un graduado universitario, no basta con saber la disciplina. Se requiere también de una cosmovisión, sensibilidad, capacidad interrogativa, un compromiso con la propia formación que permitan no sólo leer el presente, sino intervenir en proyectos para hacer de este mundo un lugar más humano. 